\title{
Comparison of adenoid size in lateral radiographic, pathologic, and endoscopic measurements
}

\author{
Sina Talebian ${ }^{1}$, Gholamreza Sharifzadeh ${ }^{2}$, Iraj Vakili ${ }^{3}$, Seyyed Hassan Golboie ${ }^{4}$
}

${ }^{1}$ M.D. Student Research Committee, School of Medicine, Birjand University of Medical Sciences, Birjand, Iran

${ }^{2}$ M.Sc. of Epidemiology, Assistant Professor, Social Determinants of Health Research Center, Birjand University of Medical Sciences, Birjand, Iran

${ }^{3}$ M.D. Student Research Committee, School of Medicine, Mashhad University of Medical Sciences, Mashhad, Iran

${ }^{4}$ M.D. in ENT Surgery, Assistant Professor, Department of Thorax Surgery, Faculty of Medicine, Birjand University of Medical Sciences, Vali-e-asr Hospital, Birjand, Iran

\section{Type of article: Original}

\begin{abstract}
Background: Otitis media (OM) is a major health problem that usually results from adenoid hypertrophy. Diagnosis is based on symptoms like mouth breathing and imaging studies like lateral neck radiography (LNR). Adenoid-nasopharyngeal ratio ( $\mathrm{A} / \mathrm{N}$ ratio) is one of the most important and most widely used criteria in LNR study that could estimate the real size of adenoid gland measurements. However, there are huge controversies regarding LNR rules in the management of patients with OM.

Objective: This study aimed to determine Adenoid Nasopharyngeal Ratio (A/N ratio) in children with otitis media with effusion (OME) and its relation with different factors.

Methods: This was a cross-sectional study on OME suspected children who needed adenoidectomy. The study was conducted from the fall to winter of 2016 on patients referred to ENT clinics of Mashhad University of Medical Sciences. Before surgery, all children underwent standard LNRs and indirect laryngoscopy to assess adenoidal size, and nasopharyngeal length, and $\mathrm{A} / \mathrm{N}$ ratio. After adenoidectomy, pathologic analysis was performed for assessment of pathologic size. SPSS 21 was used for data analyzing using Pearson's correlation, independent $t$ test and Mann-Whitney $U$ test ( $<<0.05$ was considered significant).

Results: A total of 27 children were enrolled. Most of the patients were male $(70.4 \%$, mean age $=7.81 \pm 2.52$ year). All patients in the study were symptomatic and the most frequent symptom was mouth breathing (100\%). The mean $\mathrm{A} / \mathrm{N}$ ratio, pathologic adenoid size, and laryngoscopic adenoid size were $0.825 \pm 0.099,18.22 \pm 5.97$, and $5.33 \pm 19.15 \mathrm{~mm}$. There was a significant correlation between the $\mathrm{A} / \mathrm{N}$ ratio laryngoscopic adenoid size $(\mathrm{r}=+0.46$, $\mathrm{p}=0.01)$ and pathologic adenoid size $(\mathrm{r}=+0.44, \mathrm{p}=0.02)$.

Conclusions: The results of this study showed that $\mathrm{A} / \mathrm{N}$ ratio can be used to estimate the actual size of the adenoid gland and the necessity of adenoidectomy. Considering the reasonable costs and availability of this diagnostic method, researchers recommend using this procedure in assessment of patients with OME.

Keywords: Otitis media, Adenoid hypertrophy, Effusion, Rhinoscopy
\end{abstract}

\section{Introduction}

Otitis media $(\mathrm{OM})$ is one of the most important public health problems, especially in the pediatric population of developing countries $(1,2)$. Untreated chronic serous OM is a serious threat to hearing ability and its incidence has increased dramatically in recent years (3). Otitis media with effusion (OME) is generally resulted from lymphoid tissue overgrowth in nasopharynx, chronic sinus infection, and allergies (4). Nevertheless, inadequate treatment of acute or subacute suppurative $\mathrm{OM}$ is an important factor in increasing prevalence of chronic serous OM, causing mild and asymptomatic infection, and results in thick mucoid effusion remains in the ear (1). Symptoms of OME are generally insignificant including hearing loss with fluctuations during acute respiratory infections, feeling of heaviness or fullness in the ear as well as impairment of perception of sounds (5). The tympanic membrane harbors minor changes and possibly a slight fading in the tympanic membrane may be presented in autoscopy (6). Limited

\section{Corresponding author:}

Dr. Seyyed Hassan Golboie, Department of ENT, Valie Asr Hospital, Ghaffari Street, Birjan, South Khorasan, Iran. Tel: +98.9378545085, Email: Golboiem@bums.ac.ir

Received: January 28, 2017, Accepted: December 11, 2017, Published: June 2018

iThenticate screening: March 15, 2017, English editing: April 12, 2018, Quality control: April 14, 2018

(c) 2018 The Authors. This is an open access article under the terms of the Creative Commons Attribution-NonCommercialNoDerivs License, which permits use and distribution in any medium, provided the original work is properly cited, the use is non-commercial and no modifications or adaptations are made. 
movement of the tympanic membrane in tympanometry and pneumatic otoscopy are the most useful otoscopic findings (7). The audiometric evaluation has a diagnostic role and shows conductive hearing loss. Long-term chronic serous OM may lead to formation of cholesteatoma, tympanic membrane perforation, fibrosis in the middle ear, and Tympanosclerosis which all of them may result in a permanent hearing loss (8). Therefore, timely diagnosis and treatment of patients suffering from acute or chronic OME is crucial (9). Adenoid hypertrophy is one of the most important causes of OME. This clinical condition can cause a wide range of symptoms such as runny nose, hypernasality, OME, sleep disorders and mouth breathing $(10,11)$. These symptoms indicate association of adenoid hypertrophy with obstruction of upper respiratory tract. Adenoid hypertrophy is one of the most important indications for adenoidectomy which is one of the most common otorhinolaryngological surgeries (12). Surgical removal of a hypertrophic adenoid gland causes disappearance of the respiratory symptoms and normal craniofacial development $(13,14)$. Chronic otitis media and adenotonsillitis has been considered as a chronic infective state recently which was evidenced in conditions due to biofilms or small colony variants (15). The role of biofilms in the persistence of chronic mucosal-based ear, nose, and throat-related infective disorders was previously identified in otitis media and adenotonsillitis. The efficacy of adenotonsillectomy on OME has been demonstrated by several clinical trial studies $(16,17)$. Briefly, it was proposed that patients bearing recurrent or chronic OME may benefit from adenoidectomy due to the removal of an infectious source in a large adenoidal mass which are correlated with each other (18). Despite the numerous studies which were performed on the diagnostic methods for assessment of adenoid size, there is no standard and reliable method (19-23). Two of these methods are cavum X-ray and orthodontic cephalometric teleradiographies including lateral neck radiography (LNR) $(19,20)$. Although these methods are inexpensive and available, they have limited role in the exact assessment of areas such as the ears (24). To try to overcome this drawback, to date, numerous criteria in radiographs of this area have been examined. Adenoid-nasopharyngeal ratio (A/N ratio) is one of the most important and most widely used criteria $(19,22,23,25$ 27), albeit, the results of various studies were inconsistent. In studies by Wormald et al. no relation was observed between $\mathrm{A} / \mathrm{N}$ ratio and size of adenoid in direct nasal endoscopy $(22,23)$. However, in a study by Cho et al. and a study by Caylakli et al., a significant correlation was reported between these two variables $(26,27)$. Kolo et al. showed that there was an insignificantly direct poor correlation between symptoms of children with airway obstruction symptom and radiological findings (28). Results of a study by Lertsburapa et al. showed that there was a positive significant correlation between results of adenoid gland measurements during surgery and $\mathrm{A} / \mathrm{N}$ ratio in LNR, and adenoid size could be estimated with high accuracy by using $\mathrm{A} / \mathrm{N}$ ratio (29). However, this method sometimes overestimates adenoid size when it is too small and or it is too big (29). In another study in India it was proven that $\mathrm{A} / \mathrm{N}$ ratio $\geq 0.7 \mathrm{~mm}$ is an adenoidectomy indicator (21). Although, some studies indicated nasopharyngeal assessment using LNR, lack of accuracy and hence $\mathrm{A} / \mathrm{N}$ ratio in assessment of adenoid hypertrophy $(19,30)$. This study aimed to determine $\mathrm{A} / \mathrm{N}$ ratio in children with $\mathrm{OME}$ and its relation with different factors.

\section{Material and Methods}

\subsection{Study Design and setting}

This was a cross-sectional study on OME suspected children who needed adenoidectomy. The study was conducted from the fall to winter of 2016 on patients referred to ENT clinics of Mashhad University of Medical Sciences. All 4-13 year old children with complaints of hearing loss, conductive hearing loss of about $300 \mathrm{dp}$ in tuning fork test, presence of diagnostic otoscopic criteria of otitis media with effusion (retraction of tympanic membrane, bulging tympanic membrane, membrane turbidity with reduced mobility with Valsalva maneuver, swollen malleus mostly with redness, and air-fluid level, and presence of tympanometry criteria of OME (Type B tympanograms) were included in the study. Exclusion criteria consisted of children dissent from participating in the study, history of otorhinolaryngological surgeries, tympanic membrane perforation, acute otitis media, chronic otitis media, congenital anomalies of external ear, history of allergic rhinitis, nasal septal deviation, and congenital hearing loss.

\subsection{Sample size}

Sample size was estimated 17 persons based on the Caylakli et al.'s study (27), considering $\alpha=0.050$ (type I error) and $\beta=0.200$ (type II error) and $\mathrm{r}=0.64$ (correlation of $\mathrm{A} / \mathrm{N}$ ratio and intraoperative findings of adenoid size).

\subsection{Data collection}

Data was collected using a questionnaire that included sex, age, and OME symptoms (snoring, mouth breathing, and hyponasality) which were filled by visiting children and their parents while taking medical history. Adenoid size, nasopharyngeal size and adenoid nasopharyngeal ratio were obtained using radiographs and physical examination. 


\subsection{Patient examination}

All included patients underwent lateral neck radiography. To calculate the adenoidal size (A) the distance between the outermost point of adenoid shadow and the line along the spheno/basiocciput (line B) was measured. To obtain nasopharyngeal size $(\mathrm{N})$ the distance between posterior edge of the hard palate and line B was measured. Adenoid nasopharyngeal ratio was calculated by dividing adenoidal size to nasopharyngeal size (Figure 1). All LNRS were reported by one radiologist using the Fujioka method. In order to reduce error, all measurements were performed by the same person using the same standard grading line in millimeters, and values less than a millimeter were rounded using standard statistical methods. After extracting values from radiographs, they were multiplied by X-ray machine magnification (obtained from radiologist) to calculate real values, and resulting numbers were used in the analysis. After initial diagnosis, patients were examined by a head and neck surgeon in the operation room using indirect laryngoscopy (after anesthesia and prior to surgery) and laryngoscopic size of adenoidal was assessed. Thereafter, patients underwent adenoidectomy and tissues were sent to the pathology laboratory for pathologic evaluation. All samples were reviewed and approved by one pathologist.

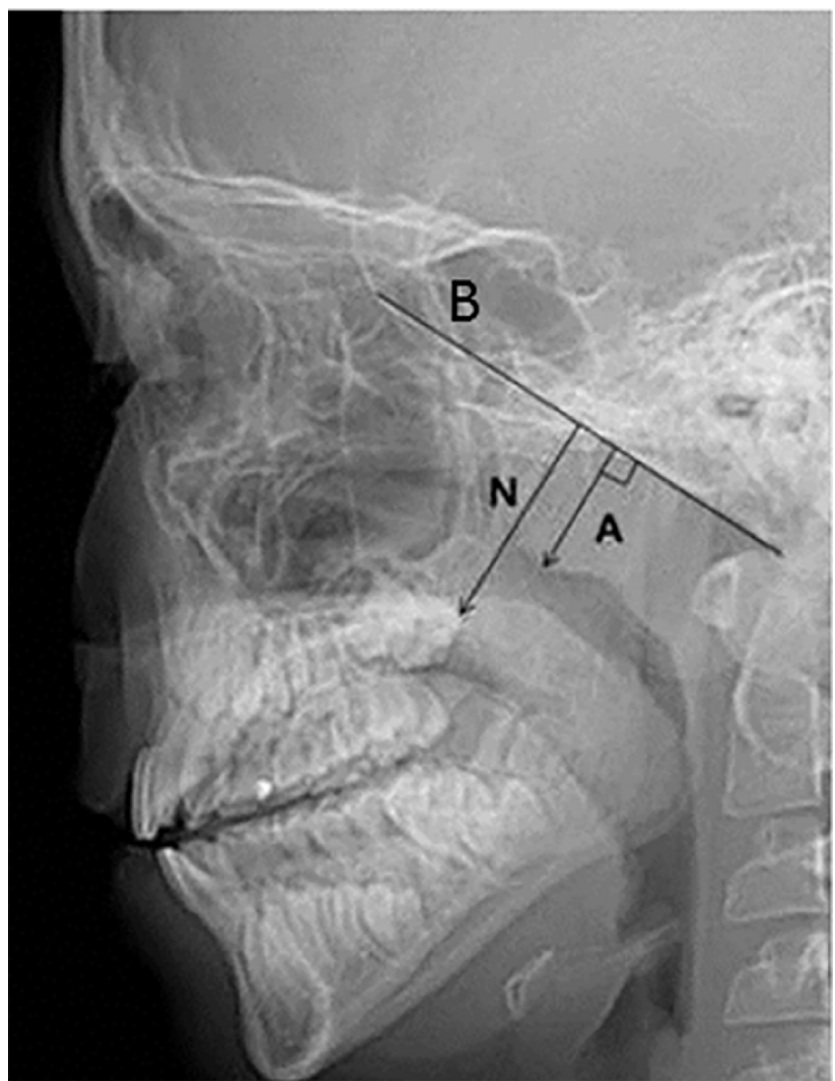

Figure 1. Estimation of the $\mathrm{A} / \mathrm{N}$ ratio (Fujioka Method). The distance between the outermost point of convexity of adenoid shadow and spheno/basiocciput (A) is divided by the distance between spheno/basiocciput and posterior end of the hard palate

\subsection{Ethical considerations}

Approval from the Ethics Committee of the medical school at BUMS was obtained for this study. Written informed consent was obtained from legal guardians of children in order to include children in the study. All collected data were anonymous and were returned to the patients after surveying and were only used for research purposes.

\subsection{Statistical Analyses}

Data were analyzed by IBM( SPSS $\subset$ Statistics version 21 (IBM@ Corp., Armonk, NY, USA) and were described using frequency tables, graphs and mean indices and standard deviation. Before Analysis, normal distribution of mean values was analyzed using the Kolmogorov-Smirnov test, indicating that radiologic adenoid size and A/N ratio had normal distribution ( $\mathrm{p}=0.13$ and 0.14 , respectively). On the other hand, radiologic nasopharyngeal size had nonsymmetric distribution $(\mathrm{p}=0.03)$. To determine the relationship between the $\mathrm{A} / \mathrm{N}$ ratio and adenoidal size, Pearson's correlation coefficient was used. To compare mean $\mathrm{A} / \mathrm{N}$ ratio with radiologic adenoid size, independent $\mathrm{t}$-test was 
http://www.ephysician.ir

performed. Due to non-symmetric distribution, to compare the average size of radiologic nasopharyngeal, MannWhitney $U$ test was used for quantitative variables. Significance level was considered $p \leq 0.05$.

\section{Results}

A total of 27 children were included in the study which consisted of 19 males (70.4\%) and 8 females (29.6\%). Mean age of patients was $7.81 \pm 2.52$ and the majority of patients were at least 8 years old (14 persons, $51.9 \%$ ) (Table 1). Regarding the symptoms of adenoidal hypertrophy, all patients in this study were symptomatic (27 cases, $100 \%)$. The most common symptoms were mouth breathing (27 cases, 100\%), snoring ( 25 cases, $92.6 \%$ ), and hyponasal speech (8 cases, $29.6 \%)$, respectively (Table 2$)$. The results showed that the average of radiologic adenoid size, the radiologic nasopharyngeal size, and radiologic $\mathrm{A} / \mathrm{N}$ ratio were $18.69 \pm 3.29(12.5-30) \mathrm{mm}, 22.75 \pm 3.62(17-33) \mathrm{mm}$, and $0.825 \pm 0.099$ (0.54-1), respectively. Pathologic adenoid size was $18.22 \pm 5.97 \mathrm{~mm}(10-25)$ and endoscopic adenoid size was $19.15 \pm 5.33 \mathrm{~mm}$ (10-30). No significant difference was detected comparing average $\mathrm{A} / \mathrm{N}$ ratio in children with OME based on age $(\mathrm{p}=0.9, \mathrm{t}=0.072)$. Average adenoid size in patients younger than seven years was $18.72 \pm 4.46 \mathrm{~mm}$ and in patients older than eight years was $18.66 \pm 1.84 \mathrm{~mm}(\mathrm{p}=0.9, \mathrm{t}=0.045)$. No significant difference was seen in average nasopharyngeal size of these groups $(\mathrm{p}=0.6)$. Male adenoid size on LNR was significantly higher than female $(19.41 \pm 3.27 \mathrm{~mm}$ vs. $16.97 \pm 2.84 \mathrm{~mm}, \mathrm{p}=0.08)$. Nasopharyngeal size and $\mathrm{A} / \mathrm{N}$ ratio of male and female patients showed no significant difference (Table 3). There was no significant relation between $\mathrm{A} / \mathrm{N}$ ratio, adenoid size and nasopharyngeal size in respect of different symptoms (Table 4). There was a positive significant correlation between $\mathrm{A} / \mathrm{N}$ ratio and endoscopic adenoid size $(\mathrm{r}=+0.46, \mathrm{p}=0.01)$. Also, $\mathrm{A} / \mathrm{N}$ ratio and pathologic adenoid size showed positive significant correlation $(r=+0.44, \mathrm{p}=0.02)$ (Table 5).

Table 1. Demographic data distribution of study cohort

\begin{tabular}{|l|l|l|l|}
\hline \multicolumn{2}{|l|}{ Variable } & Frequency & Percentage \\
\hline \multirow{3}{*}{ Sex } & Male & 19 & 70.4 \\
\cline { 2 - 4 } & Female & 8 & 29.6 \\
\cline { 2 - 4 } & Sum & 27 & 100 \\
\hline \multirow{3}{*}{ Age (year) } & $\leq 7$ & 13 & 48.1 \\
\cline { 2 - 4 } & $>7$ & 14 & 51.9 \\
\cline { 2 - 4 } & Sum & 27 & 100 \\
\hline
\end{tabular}

Table 2. Frequency distribution of adenoidal hypertrophy symptoms in the study cohort

\begin{tabular}{|c|c|c|c|}
\hline \multicolumn{2}{|l|}{ Variable } & Frequency & Percentage \\
\hline \multirow[t]{2}{*}{ Snoring } & Positive & 25 & 92.5 \\
\hline & Negative & 2 & 7.5 \\
\hline \multirow[t]{2}{*}{ Mouth breathing } & Positive & 27 & 100 \\
\hline & Negative & 0 & 0 \\
\hline \multirow[t]{2}{*}{ Hyponasal speech } & Positive & 8 & 29.6 \\
\hline & Negative & 19 & 70.4 \\
\hline
\end{tabular}

Table 3. Comparing average adenoidal-nasopharyngeal ratio (A/N ratio), adenoid size, nasopharyngeal size in children with otitis media with effusion (OME) according to age and sex

\begin{tabular}{|c|c|c|c|c|}
\hline \multicolumn{3}{|l|}{ Variables } & Mean \pm SD & Test statistics and p-value \\
\hline \multirow[t]{4}{*}{$\mathrm{A} / \mathrm{N}$ ratio } & \multirow[t]{2}{*}{ Age } & $\leq 7$ & $0.827 \pm 0.106$ & \multirow[t]{2}{*}{$\mathrm{t}=0.072^{1}, \mathrm{p}=0.9$} \\
\hline & & $>7$ & $0.824 \pm 0.097$ & \\
\hline & \multirow[t]{2}{*}{ Sex } & Male & $0.829 \pm 0.081$ & \multirow[t]{2}{*}{$\mathrm{t}=0.319^{1}, \mathrm{p}=0.75$} \\
\hline & & Female & $0.816 \pm 0.141$ & \\
\hline \multirow[t]{4}{*}{ adenoid size $(\mathrm{mm})$} & \multirow[t]{2}{*}{ Age } & $\leq 7$ & $18.72 \pm 4.46$ & \multirow[t]{2}{*}{$\mathrm{t}=0.045^{1}, \mathrm{p}=0.9$} \\
\hline & & $>7$ & $18.66 \pm 1.84$ & \\
\hline & \multirow[t]{2}{*}{ Sex } & Male & $19.41 \pm 3.27$ & \multirow[t]{2}{*}{$\mathrm{t}=1.83^{1}, \mathrm{p}=0.08$} \\
\hline & & Female & $16.97 \pm 2.84$ & \\
\hline \multirow{4}{*}{$\begin{array}{l}\text { Nasopharyngeal size mean rank } \\
(\mathrm{mm})\end{array}$} & \multirow[t]{2}{*}{ Age } & $\leq 7$ & 13.15 & \multirow[t]{2}{*}{$\mathrm{z}=-0.536^{2}, \mathrm{p}=0.6$} \\
\hline & & $>7$ & 14.79 & \\
\hline & \multirow[t]{2}{*}{ Sex } & Male & 15.53 & \multirow[t]{2}{*}{$\mathrm{z}=-1.547^{2}, \mathrm{p}=0.1$} \\
\hline & & Female & 10.38 & \\
\hline
\end{tabular}

1: Independent-samples t-test, Mann-Whitney U test 
Table 4. Comparing average adenoidal-nasopharyngeal ratio (A/N ratio), adenoid size, nasopharyngeal size in children with otitis media with effusion (OME) according to different symptoms

\begin{tabular}{|l|l|l|l|l|}
\hline Variables & Yes & No & $\begin{array}{l}\text { Test statistics and } \mathrm{p} \text { - } \\
\text { value }\end{array}$ \\
\hline \multirow{3}{*}{ Snoring } & $\begin{array}{l}\text { Adenoidal-nasopharyngeal ratio } \\
(\text { Mean } \pm \text { SD) }\end{array}$ & $0.82 \pm 0.1$ & $0.84 \pm 0.02$ & $\mathrm{t}=-0.5^{1}, \mathrm{p}=0.6$ \\
\cline { 2 - 5 } & Adenoid size & $18.78 \pm 3.41$ & $17.55 \pm 0.91$ & $\mathrm{t}=0.3^{1}, \mathrm{p}=0.7$ \\
\cline { 2 - 5 } & Nasopharyngeal size (mean rank) & 14.4 & 9 & $\mathrm{z}=-0.9^{2}, \mathrm{p}=0.3$ \\
\hline \multirow{2}{*}{$\begin{array}{l}\text { Hyponasal } \\
\text { speech }\end{array}$} & $\begin{array}{l}\text { Adenoidal-nasopharyngeal ratio } \\
(\text { Mean } \pm \text { SD) }\end{array}$ & $0.78 \pm 0.06$ & $0.80 \pm 0.10$ & $\mathrm{t}=-1.65^{1}, \mathrm{p}=0.1$ \\
\cline { 2 - 6 } & Adenoid size & $19.46 \pm 3.41$ & $18.36 \pm 2.66$ & $\mathrm{t}=-0.78^{1}, \mathrm{p}=0.4$ \\
\cline { 2 - 5 } & Nasopharyngeal size (mean rank) & 11.75 & 14.95 & $\mathrm{z}=-0.9^{2}, \mathrm{p}=0.3$ \\
\hline
\end{tabular}

1: Independent-samples t-test, Mann-Whitney U test

Table 5. Determining correlation between adenoidal-nasopharyngeal ratio ( $\mathrm{A} / \mathrm{N}$ ratio) and adenoid size in Intraoperative and pathology examination

\begin{tabular}{|l|l|l|l|}
\hline Variable & $\mathrm{n}$ & $(\mathrm{Mean} \pm \mathrm{SD})$ & Test statistics and $\mathrm{p}$-value \\
\hline Intraoperative size & 27 & $19.15 \pm 5.33$ & $\mathrm{r}=+0.46, \mathrm{p}=0.01$ \\
\hline A/N ratio & 27 & $0.825 \pm 0.099$ & \\
\hline Pathological size & 27 & $18.22 \pm 5.97$ & $\mathrm{r}=+0.44, \mathrm{p}=0.02$ \\
\hline A/N ratio & 27 & $0.825 \pm 0.099$ & \\
\hline \multicolumn{4}{|c|}{ 1: Pearson product moment Correlation test } \\
\hline
\end{tabular}

\section{Discussion}

The objective of this study was to determine the $\mathrm{A} / \mathrm{N}$ ratio in children with OME and its correlation with intraoperative and pathologic adenoidal size, symptoms, age, and sex. The results of this study indicated that there was a positive significant correlation between $\mathrm{A} / \mathrm{N}$ ratio and endoscopic and adenoid pathological size. However, no correlation was found between this ratio and other variables such as different symptoms, sex and age. In a study by Caylakli et al. evaluating the relation between $\mathrm{A} / \mathrm{N}$ ratio and adenoid hypertrophy, it was reported that there was a positive significant correlation between $\mathrm{A} / \mathrm{N}$ ratio and endoscopic examination results $(\mathrm{r}=0.551$ and $\mathrm{p}<0.0001)$. The results of the study by Caylakli et al. confirm this study's results about correlation of $\mathrm{A} / \mathrm{N}$ ratio with adenoid gland measurement during surgery and pathological examination (27). Lertsburapa et al. performed a study on the relation of adenoid size in nasal endoscopy with radiographic measurements, and reported findings in line with this study that there was a positive significant correlation between these variables and concluded that LNR could estimate adenoid size accurately (29). However, it should be considered that LNR measurements overestimate adenoid size if the actual size of adenoid is too small. Also, adenoid size could be underestimated in LNR assessment if the actual adenoid size is too big (29). There are some studies that have reported results against ours $(19,30)$. Mlynarek et al. compared radiologic adenoid size using LNR and size of adenoid in direct video rhinoscopy and reported that increase in $\mathrm{A} / \mathrm{N}$ ratio was not consistent with adenoid enlargement in video rhinoscopy (19). In a study by Al-Kindy et al. on significance of radiological findings in treatment of children with adenoidal hypertrophy, they reported that about $30 \%$ of symptomatic children who had an increased $\mathrm{A} / \mathrm{N}$ ratio underwent adenoidectomy (30). In other words; more than $70 \%$ of patients who had adenoidal hypertrophy based on symptoms and radiologic assessment were treated medically and they concluded that radiological findings had a limited role in the management of adenoidal hypertrophy, and recommend against their routine use (30). Although the Al-Kindy et al. findings are justifiable considering that lateral neck radiographs of patients showed an increase in adenoid size resulting from acute inflammation, after medical treatment, acute adenoid inflammation improved and adenoidectomy was not necessary, hence there was no correlation between patients' symptoms and adenoid nasopharyngeal ratio (30). Likewise, a weak insignificant correlation was found between symptom presence and radiological findings by Kolo et al. studying radiographic evaluation of children with obstructive adenoid (28). Also in another study by Mlynarek et al. on evaluation and comparison of adenoid measurement using lateral neck radiography and direct video rhinoscopy, no correlation between adenoid nasopharyngeal ratio and symptom presence was found (19). Unlike this study, Gangadhara Somayaji et al. evaluated significance of adenoid nasopharyngeal ratio in assessment of adenoid hypertrophy in children and it was found that patients presenting with mouth breathing and snoring symptoms had a significantly larger adenoid (31). Regarding the study limitations, we should say that the main limitations of this study were the small sample size and insufficient coorporation of parents. 


\section{Conclusions}

Our study showed that $\mathrm{A} / \mathrm{N}$ ratio had significant correlation with real adenoid measurement (pathologic and surgical measurement). Lateral neck radiography is inexpensive, available and has negligible side effects, which could be used in management of adenoid hypertrophy treatment. For further research, we recommend children with adenoid hypertrophy symptoms whose adenoid enlargement was confirmed using lateral neck radiography and adenoid nasopharyngeal ratio undergo medical treatment before adenoidectomy. Then repeat radiological examination on patients and assess adenoid and pharyngeal size and their ratio and their changes. At the end, assess correlation of $\mathrm{A} / \mathrm{N}$ ratio changes with adenoidectomy necessity.

\section{Acknowledgments:}

Research reported in this article was supported by Birjand University of Medical Sciences, Faculty of Medicine, under grant number 843 , as a general practitioner thesis. Authors gratefully acknowledge Dr. Jafarian for his kind help in reporting the pathologic findings of tissues. Also, we acknowledge the great support of Dr. Abbasi in interpretation of radiologic studies. The process determination of sample size was supervised by statistics consultant of thesis (Mr. Sharifzadeh; Assistant Professor, Faculty of Medicine, BUMS) and statistical reviewer of medical faculty (Dr. Bijari; Associate Professor, Faculty of Medicine, BUMS).

\section{Conflict of Interest:}

There is no conflict of interest to be declared.

Authors' contributions:

All authors contributed to this project and article equally. All authors read and approved the final manuscript.

\section{References:}

1) Mahadevan M, Navarro-Locsin G, Tan HK, Yamanaka N, Sonsuwan N, Wang PC, et al. A review of the burden of disease due to otitis media in the Asia-Pacific. Int J Pediatr Otorhinolaryngol. 2012; 76(5): 62335. doi 10.1016/j.ijporl.2012.02.031. PMID: 22404948.

2) Prakash R, Juyal D, Negi V, Pal S, Adekhandi S, Sharma M, et al. Microbiology of Chronic Suppurative Otitis Media in a Tertiary Care Setup of Uttarakhand State, India. N Am J Med Sci. 2013; 5(4): 282-7. doi 10.4103/1947-2714.110436. PMID: 23724403, PMCID: PMC3662095.

3) Wu JF, Jin Z, Yang JM, Liu YH, Duan ML. Extracranial and intracranial complications of otitis media: 22year clinical experience and analysis. Acta Otolaryngol. 2012; 132(3): 261-5. doi: 10.3109/00016489.2011.643239. PMID: 22224578.

4) Farajzadah Sheikh A, Saki N, Roointan M, Ranjbar R, Yadyad MJ, Kaydani A, et al. Identification of Alloiococcus otitidis, Streptococcus pneumoniae, Moraxella catarrhalis and Haemophilus influenzae in Children With Otitis Media With Effusion. Jundishapur J Microbiol. 2015; 8(3): e17985. doi: 10.5812/jjm.17985. PMID: 25861433, PMC4386075.

5) Kong K, Coates HL. Natural history, definitions, risk factors and burden of otitis media. The Medical journal of Australia. 2009; 191(9 Suppl): S39-43. PMID: 19883355.

6) Baum HL. Pneumonic Otitis Media. Archives of Otolaryngology. 1935; 21(1): 96-7. doi: 10.1001/archotol.1935.00640020103013.

7) Bluestone CD. Pathogenesis of otitis media: role of eustachian tube. The Pediatric infectious disease journal. 1996; 15(4): 281-91. doi: 10.1097/00006454-199604000-00002. PMID: 8866795.

8) Hartzell LD, Dornhoffer JL. Timing of tympanoplasty in children with chronic otitis media with effusion. Current opinion in otolaryngology \& head and neck surgery. 2010; 18(6): 550-3. doi: 10.1097/MOO.0b013e32833febc4.

9) Craig JC, Williams GJ, Jones M, Codarini M, Macaskill P, Hayen A, et al. The accuracy of clinical symptoms and signs for the diagnosis of serious bacterial infection in young febrile children: prospective cohort study of 15781 febrile illnesses. BMJ. 2010; 340: c1594. doi 10.1136/bmj.c1594. PMID: 20406860, PMCID: PMC2857748.

10) Dolen WK, Spofford B, Selner JC. The hidden tonsils of Waldeyer's ring. Annals of allergy. 1990; 65(4): 244-8. PMID: 2221482.

11) Wang DY, Bernheim N, Kaufman L, Clement P. Assessment of adenoid size in children by fibreoptic examination. Clinical otolaryngology and allied sciences. 1997; 22(2): 172-7. doi: 10.1046/j.13652273.1997.00002.x. PMID: 9160934. 
12) T-Ping C, Weckx LL. ENT care of children and adolescents in the Brazilian public healthy system in three different municipalities. Braz J Otorhinolaryngol. 2008; 74(4): 571-8. doi: 10.1016/S1808-8694(15)306054. PMID: 18852984.

13) Brietzke SE, Brigger MT. Adenoidectomy outcomes in pediatric rhinosinusitis: a meta-analysis. International journal of pediatric otorhinolaryngology. 2008; 72(10): 1541-5. doi 10.1016/j.ijporl.2008.07.008.

14) Peltomäki T. The effect of mode of breathing on craniofacial growth-revisited. European Journal of Orthodontics. 2007; 29(5): 426-9. doi: 10.1093/ejo/cjm055.

15) Macassey E, Dawes P. Biofilms and their role in otorhinolaryngological disease. J Laryngol Otol. 2008; 122(12): 1273-8. doi: 10.1017/s0022215108002193. PMID: 18405407.

16) van den Aardweg MTA, Schilder AGM, Herkert E, Boonacker CWB, Rovers MM. Adenoidectomy for otitis media in children. Cochrane Database Syst Rev. 2010; (1): CD007810. doi: 10.1002/14651858.CD007810.pub2. PMID: 20091650.

17) Wallace IF, Berkman ND, Lohr KN, Harrison MF, Kimple AJ, Steiner MJ. Surgical treatments for otitis media with effusion: a systematic review. Pediatrics. 2014; 133(2): 296-311. doi: 10.1542/peds.2013-3228.

18) Park K. Otitis media and tonsils--role of adenoidectomy in the treatment of chronic otitis media with effusion. Advances in oto-rhino-laryngology. 2011; 72: 160-3. doi: 10.1159/000324781.

19) Mlynarek A, Tewfik MA, Hagr A, Manoukian JJ, Schloss MD, Tewfik TL, et al. Lateral neck radiography versus direct video rhinoscopy in assessing adenoid size. The Journal of otolaryngology. 2004; 33(6): 360 5. doi: 10.2310/7070.2004.03074. PMID: 15971651.

20) Kemaloglu YK, Goksu N, Inal E, Akyildiz N. Radiographic evaluation of children with nasopharyngeal obstruction due to the adenoid. The Annals of otology, rhinology, and laryngology. 1999; 108(1): 67-72. doi: 10.1177/000348949910800110. PMID: 9930543.

21) Sharifkashani S, Dabirmoghaddam P, Kheirkhah M, Hosseinzadehnik R. A New Clinical Scoring System for Adenoid Hypertrophy in Children. Iranian Journal of Otorhinolaryngology. 2015; 27(78): 55-61. PMID: 25745612, PMCID: PMC4344975.

22) Wormald PJ, Prescott CA. Adenoids: comparison of radiological assessment methods with clinical and endoscopic findings. J Laryngol Otol. 1992; 106(4): 342-4. doi: 10.1017/S0022215100119449. PMID: 1613348.

23) Chami FA. Avaliaçäo nasofibroscópica e rediológica de pacientes com hiperplasia da amígdla faríngea. Rev bras med otorrinolaringol. 1998; 5(4): 118-28.

24) Aboudara CA, Hatcher D, Nielsen IL, Miller A. A three-dimensional evaluation of the upper airway in adolescents. Orthod Craniofac Res. 2003; 6 Suppl 1: 173-5. doi: 10.1034/j.1600-0544.2003.253.x. PMID: 14606553.

25) Fujioka M, Young LW, Girdany BR. Radiographic evaluation of adenoidal size in children: adenoidalnasopharyngeal ratio. AJR American journal of roentgenology. 1979; 133(3): 401-4. doi: 10.2214/ajr.133.3.401.

26) Cho JH, Lee DH, Lee NS, Won YS, Yoon HR, Suh BD. Size assessment of adenoid and nasopharyngeal airway by acoustic rhinometry in children. J Laryngol Otol. 1999; 113(10): 899-905. doi: 10.1017/S0022215100145530. PMID: 10664704.

27) Caylakli F, Hizal E, Yilmaz I, Yilmazer C. Correlation between adenoid-nasopharynx ratio and endoscopic examination of adenoid hypertrophy: a blind, prospective clinical study. International journal of pediatric otorhinolaryngology. 2009; 73(11): 1532-5. doi 10.1016/j.ijporl.2009.07.018.

28) Kolo ES, Ahmed AO, Kazeem MJ, Nwaorgu OG. Plain radiographic evaluation of children with obstructive adenoids. European journal of radiology. 2011; 79(2): e38-41. doi: 10.1016/j.ejrad.2010.09.027.

29) Lertsburapa K, Schroeder JW Jr, Sullivan C. Assessment of adenoid size: A comparison of lateral radiographic measurements, radiologist assessment, and nasal endoscopy. Int J Pediatr Otorhinolaryngol. 2010; 74(11): 1281-5. doi 10.1016/j.ijporl.2010.08.005. PMID: 20828838.

30) Al-Kindy SA, Obaideen AO. The value of radiological examination in the management of adenoidal hypertrophy in a pediatric population. Saudi medical journal. 2003; 24(5): 504-6. PMID: 12847626.

31) Gangadhara S, Rajeshnari A, Mahaveera J. Significance of Adenoid Nasopharyngeal Ratio in the Assessment of Adenoid Hypertrophy in Children. Research in Otolaryngology. 2012; 1(1): 1-5. 